\title{
Plasma retinol-binding protein 4 and insulin resistance in overweight and obesity: effect of weight loss
}

\author{
M. Spence ${ }^{1}$, U. Bradley ${ }^{2}$, C. H. Courtney ${ }^{2}$, M. C. McKinley ${ }^{3}$, C. N. Ennis ${ }^{2}$, J. McEneny ${ }^{3}$, P. M. Bell ${ }^{2}$, \\ I. S. Young ${ }^{3}$ and S. J. Hunter ${ }^{2}$ \\ ${ }^{1}$ School of Nursing and Midwifery, Queen's University Belfast, Belfast BT9 5BN, UK, ${ }^{2}$ Regional Centre for Endocrinology \\ and Diabetes, Royal Victoria Hospital, Belfast BT12 6BA, UK and ${ }^{3}$ Nutrition and Metabolism Group, Queen's University \\ Belfast, Belfast BT12 6BJ, UK
}

The adipokine retinol-binding protein 4 (RBP4) may contribute to the pathophysiological link between obesity and insulin resistance ${ }^{(1)}$. The aim of the present study was to investigate whether plasma RBP4 mediates the improvement in insulin sensitivity following dietinduced weight loss.

Twenty-four overweight and obese subjects without diabetes (BMI 33.6 (SE 0.8) $\mathrm{kg} / \mathrm{m}^{2}$, age 39 (SE 2) years) were randomly assigned to consume one of two energy-restricted diets (low-carbohydrate or low-fat; twelve subjects per group) for 8 weeks. Throughout the intervention food was provided (in pre-weighed portions) to achieve a minimum weight loss of $0.5 \mathrm{~kg} / \mathrm{week}$.

Plasma RBP4 levels were measured before and after diet-induced weight loss using a commercially-available sandwich ELISA. Insulin sensitivity and body composition were also assessed by the euglycaemic-hyperinsulinaemic clamp and dual-energy X-ray absorptiometry scan respectively.

There was no significant between-group (twelve subjects per group) difference in weight loss or insulin resistance as a result of the diet assignment. For the group as a whole $(n 24)$, RPB4 levels did not correlate with insulin sensitivity at baseline $(r 0.16, P=0.48)$ or after diet-induced weight loss $(r 0.07, P=0.75)$. Weight loss $(7 \%$ decrease of initial body weight; $P<0.01)$ significantly improved insulin sensitivity (by $13 \% ; P=0.03$ ) and reduced plasma RBP4 levels (by $17 \% ; P=0.03$ ). However, there was no correlation between weightloss induced changes in RBP4 levels and the change in insulin sensitivity or between plasma RBP4 and measures of adiposity.

\begin{tabular}{|c|c|c|c|c|c|}
\hline \multirow[b]{2}{*}{ Variable } & \multicolumn{2}{|c|}{ Pre-diet $(n$ 24) } & \multicolumn{2}{|c|}{ Post diet ( $n$ 24) } & \multirow[b]{2}{*}{$P$} \\
\hline & Mean & $\mathrm{SE}$ & Mean & $\mathrm{SE}$ & \\
\hline Weight $(\mathrm{kg})$ & 94.6 & 2.7 & 87.7 & 2.5 & $<0.01$ \\
\hline BMI $\left(\mathrm{kg} / \mathrm{m}^{2}\right)$ & 33.6 & 0.8 & 31.2 & 0.7 & $<0.01$ \\
\hline Body fat $(\%)$ & 41.0 & 1.3 & 39.3 & 1.4 & $<0.01$ \\
\hline Clamp glucose infusion rate $(\mu \mathrm{mol} / \mathrm{kg} / \mathrm{min})$ & 26.0 & 1.8 & 29.3 & 1.6 & 0.03 \\
\hline RBP4 $(\mu \mathrm{g} / \mathrm{ml})$ & 30.4 & 2.2 & 25.3 & 1.7 & 0.03 \\
\hline
\end{tabular}

In conclusion, weight loss following acute energy restriction is associated with a reduction in plasma RBP4 levels. However, the present study does not support a role for RBP4 in determining insulin resistance or influencing dietary-mediated modulation of insulin sensitivity.

1. Graham TE, Yang Q, Bluher M et al. (2006) N Engl J Med 354; 2552-2563. 